\title{
The Presence of an Exercise Instructor or Group Members Affects Physical Self-Concept and Physical Self-Esteem: An Experimental Study in the Elderly
}

\author{
Jens Kleinert1, Fabian Pels1, Leslie Podlog2 \\ ${ }^{1}$ Institute of Psychology, German Sport University Cologne, Cologne, Germany \\ ${ }^{2}$ University of Utah, Salt Lake City, USA \\ Email: kleinert@dshs-koeln.de
}

Received 24 April 2014; revised 11 June 2014; accepted 23 June 2014

Copyright (C) 2014 by authors and Scientific Research Publishing Inc.

This work is licensed under the Creative Commons Attribution International License (CC BY). http://creativecommons.org/licenses/by/4.0/

(c) $\underset{\mathrm{EY}}{\mathrm{ir}}$ Open Access

\section{Abstract}

Background: Physical self-concept and physical self-esteem are important sources of general selfesteem and overall health. Evidence indicates that exercise leads to an enhancement in physical self-concept and physical self-esteem. Until now however, it remained unclear whether the beneficial effects of exercise were impacted by different types of exercise environments. Thus, the purpose of this study was to experimentally investigate, whether the presence or absence of an instructor or other group members influenced elder adults' physical self-concept and esteem. Method: Participants were 46 women and 20 men (Mean age $65.4, \mathrm{SD}=4.36$ ) who were randomly assigned to one of four experimental groups differing across two factors-group versus no-group and instructor versus no-instructor. Participants took part in an 8-week-walking program with a comparable number of training sessions across the four experimental groups. Physical self-concept and physical self-esteem were assessed both pre and post exercise intervention. Results: Descriptively, the highest improvement in physical self-concept and esteem were observed in the instructor/no-group and the no-instructor/group condition. Between these two conditions, no significant difference of change was observed. Moreover, no improvement was observed when both instructor and group were present. Conclusion: Effects of either instructor presence or group presence may be explained by mechanisms of social integration and social support. An unexpected absence of effects on self-concept and esteem under the instructor/group condition are explained with reference to an individual's cognitive dissonance caused by the need to adapt to different exercise oriented goals or attitudes of the instructor and the group members which might hinder the positive development of the self. 


\section{Keywords}

\section{Physical Self-Esteem, Physical Self-Concept, Social Environment, Exercise, Group Instructor}

\section{Introduction}

There seems to be no doubt, that one's self-concept and self-esteem are important for health [1]. Moreover, it is apparent that the presence of others in health-related environments (e.g., the exercise environment) may impact self-concept and self-esteem [2]. The mere presence of others in the exercise environment may, however, be less relevant in its impact on an individual's self-concept and esteem than the issue of "who" such individuals are. Presently, however, it is unclear whether all individuals operating within the exercise environment have an equal impact on the self-concept and esteem levels of exercise participants. Thus, in the context of an exercise program, the purpose of the present experiment is to examine the relative impact of the presence of certain individuals-group members, an instructor, or both—on the physical self-concept and self-esteem of elderly individuals participating in an 8-week exercise program. Specifically, we assume that the well-investigated effect of exercise on self-concept and self-esteem [3] depend not only on whether or not others are present, but on whom such individuals are.

In terms of the rationale for the present study two main considerations are important to address. First, selfconcept and self-esteem have emerged as two of the strongest predictors of mental health and subjective wellbeing [1] [4]. Individuals evaluating themselves in a positive way report higher levels of mental health (e.g., emotional stability, hardiness, controllability) and lower levels of mental disorders (e.g., depression, anxiety; [2]). Second, physical self-esteem in the elderly is of special interest, since research has shown that both general self-esteem and physical self-esteem declines markedly from the 60s to the 80s [5] [6]. This decline of self-esteem in older persons may not only impair health itself, but have a strong link to unhealthy behaviors (e.g., a sedentary life style [7]), which in turn represent additional risks for health.

Physical self-concept and physical self-esteem. Physical self-esteem (often used synonymously with physical self-worth) is strongly related—albeit distinct from—physical self-concept. While self-concept is a self-description, self-esteem is self-evaluative in nature. More specifically, physical self-concept includes a description and a self-perception (e.g., self-descriptions of individual physical properties, attributes and behaviors). Physical self-esteem on the other hand, reflects an individual's evaluation of his or her own physical attributes [3]. A further distinction between physical self-concept and physical self-esteem is that the former can be differentiated into different aspects of the physical self (e.g., endurance, strength), whereas the latter is generally conceived of as an overall evaluation of the various components of one's physical self-concept [8].

These conceptual considerations led Sonstroem and Morgan [9] to develop a hierarchical model in which the authors argued that descriptions or beliefs about physical competencies (i.e., physical self-concept) are a prerequisite for the enhancement of physical self-esteem. Despite these theoretical distinctions between physical selfconcept and physical self-esteem, empirically researchers have found strong overlaps between the two constructs [8] [10].

Exercise and enhancement of physical self-concept and self-esteem. The assumption that exercise leads to an enhancement in physical self-concept and/or self-esteem has been empirically demonstrated (see [11] for a review in older adults). Most of the research in this area, however, has been conducted with middle age adults or youth [3]. With the exception of unpublished doctoral studies, Fox [3] found no published randomized controlled studies investigating the effects of exercise on physical self-concept or esteem in the elderly. One exception is a study by McAuley and colleagues who reported exercise induced physical self-esteem benefits in the elderly [12]. In this study participants took part in either a walking program or a toning exercise program, three times per week over a 6-month period. With both exercise groups the authors found increases in self-reported domain-specific esteem (domains: body, strength, condition), general physical esteem, and global esteem. In conclusion, research on the effects of exercise on elderly individuals' physical self-esteem and physical selfconcept remains noticeably deficient [5] [13]. As indicated, given the decline in physical self-esteem among elder adults and the likely implications of such a decline for a reduction in physical activity, creating exercise environments that optimize elder adults' self-concept and esteem is of clear importance. 
Physical self-esteem, self-concept, and the exercise environment. With regard to the present study, it is important to ask, why would the presence of others in the exercise environment (e.g., an exercise program for the elderly) have an influence on physical self-concept and self-esteem development? The answer to this question may be better understood by referring to Cohen's [14] conceptual considerations on the link between social relationships and health outcomes (e.g., enhancements of self-concept). In particular, the constructs of social integration and social support may be two important mechanisms that help explain the impact of the exercise environment on the development of elder adults' physical self-concept and esteem, the subject of the present investigation. Social integration refers to the feeling of belongingness and being part of the group. In this regard, groups are functional since they help to "fulfill a need for positive self-esteem by allowing one to construct a social identity which is evaluatively positive” [15]. Hogg's [15] conceptualization of social identity is especially germane for athletes and exercisers, many of whom develop positive self-evaluations through their affiliation with a particular sport, team or exercise group [16] [17].

Social support on the other hand, refers to emotional and instrumental support in coping with external demands. Specifically, related others help the individual directly (i.e., support in solving tasks) or indirectly (i.e., reducing demands) to act effectively and successfully. In the domain of exercise, such perceived effects, success, or competencies lead to an enhancement of physical self-efficacy, control beliefs [4], and self-evaluation [9]. Furthermore, for the elderly, McAuley showed that social support during an exercise program had positive effects on well-being [18].

In summary, the links between the type of exercise environment and the development of physical self-concept and esteem may be explained by principally different mechanisms, namely social integration or social support. Regardless of the mechanisms by which (i.e., "how") the presence of others influences physical self-concept and esteem among elderly individuals involved in a physical activity program, researchers have yet to investigate the issue of "who" influences physical self-concept and self-esteem to the greatest extent-the instructor or other exercise group members. Given that exercisers may choose to exercise alone, in groups, or in structured programs led by a fitness leader, examining the impact of different social environments on elder adults' self-concept and self-esteem has important implications for their well-being and sustained exercise involvement. Therefore, we designed an experiment to test the effect of two social conditions on physical self-concept and esteem changes, namely an "instructor" condition (i.e., with and without an instructor) and a "group" condition (i.e., exercising alone or as part of a group). Furthermore, regarding the hierarchical construction of the physical self-esteem, as dependent variables, we also tested distinct and specific parts of the physical self-concept (e.g., endurance, strength) as well as global physical self-esteem (i.e., self-evaluation of general athleticism). In general, we expected the presence of others-be it a group instructor and group members-to have a positive impact on the development of elder adults' physical self-concept and esteem. However, since previous research has yet to address the issue of which individuals (instructor versus group) or which constellation of individuals (instructor and group, instructor/no-group, no-instructor/group, no-instructor/no-group) has the strongest effects on self-concept and esteem, we did not advance specific hypotheses on this issue.

\section{Method}

\subsection{Participants}

In total, 92 elderly individuals (57 females and 35 males) agreed to participate. Dropouts during the walking program (17 persons) and missing data (nine persons) resulted in a final sample size of 66 participants (46 females and 20 males) ranging in age from 59 to 81 years $(M=65.42, S D=4.35)$. Except for one participant, all were physically active in some type of leisure time activity (e.g., hiking, gardening) at least once per week. Only nine persons, however, were previously active in regular exercise activities (e.g. in a sports club) at least once per week at the time of the investigation. Forty-five participants took medication regularly and 42 reported having a chronic disease (e.g., cardiovascular disease, rheumatic disease).

\subsection{Treatment}

All participants took part in a walking program after being instructed in correct walking techniques and important training principles. In particular, all participants received training information regarding warm-up procedures, how to find the optimal training intensity, and signals of overreaching (e.g., complaints). In terms of the 
optimal training intensity, participants were educated on how to assess their pulse control (130 - $150 \mathrm{bpm})$ and a moderate rate of subjectively perceived exertion (RPE $=12$ - 14; [19]). The program lasted eight weeks with an average of three training sessions per week. The walking program took place in a natural setting (forested parkland adjacent to the university sports centre). The training intensity in the group condition was determined based on an average of the physical fitness levels of group members. Each training session lasted approximately 30 to 45 minutes with an advised training intensity aimed at improving the basic endurance levels of participants. For ethical and medical reasons, members of the study team were available during the first two weeks of the exercise program to answer any questions the participants had, regardless of the experimental condition.

Treatment design. The presence of an instructor and a group during the walking sessions was manipulated via two between-subject-factors-factor "instructor" and factor "group". Each factor was subdivided into two levels ( $2 \times 2$ experimental conditions) with one level reflecting an "absence" and one level reflecting a "presence".

Manipulation of instructor presence. The factor "instructor" implied either the presence or absence of a professional fitness instructor. Among those training with an instructor and a group, participants trained three times per week, led by an instructor who implemented a predefined exercise regimen (all instructors of the study had been briefed for the exercise program before the beginning of the study). Due to organizational issues, participants who walked individually but with an instructor (instructor/no-group condition) were required to walk without the presence of the instructor in $15 \%$ - $20 \%$ of the exercise sessions. For participants in the no-instructor condition, such individuals determined their training dates and training area on their own. In terms of training duration and training intensity, participants in the no-instructor condition were instructed to consider the training principles highlighted in the treatment section described above.

Manipulation of group presence. The factor "group" implied either the presence or the absence of other study participants during the walking sessions. In the group condition, participants walked together with other participants in groups of four to eight members. The group sizes varied as a result of participant drop-out over the course of the 8-week program as well as organizational issues (e.g., conflicting obligations among study participants). In the no-group condition, participants walked independently without peers.

\subsection{Measures}

Physical self-concept. Physical self-concept was assessed using a German adaptation of the Physical Self-Description Questionnaire (PSDQ; [20]). For the self-description of physical competencies, the German version (PSK; [21]) contains five subscales: coordination (e.g. "I find it easy to control my movements"; $\alpha=0.86$ ), strength (e.g. "I am good at lifting heavy objects"; $\alpha=0.89$ ), flexibility (e.g. "My body is flexible"; $\alpha=0.88$ ), endurance (e.g. "I could be physically active for a long period of time without getting tired"; $\alpha=0.85$ ) and speediness (e.g. "Over a short distance I can run fast"; $\alpha=0.71$ ), with response options ranging from 1 (is not true) to 4 (is true) on a 4-point Likert type scale. The items of each factor were aggregated by computing a mean value for each factor. Reliability and validity of the German version have been demonstrated previously [21].

Physical self-esteem. To assess the general self-evaluation of physical competencies (i.e., physical self-esteem) the subscale "general athleticism" of the PSK was used. This subscale contains six items, that evaluate one's general physical abilities (e.g. "Other people think that I am good in sports"; $\alpha=0.85$ ). It should be mentioned, that Stiller, Würth, and Alfermann [21] did not develop this subscale for the assessment of self-esteem. However, the subscale contains many items with a strong evaluative connotation (e.g., "I am good in most sport activities", "I am better in sports than most of my friends"), which per definition (see introduction) relates to self-esteem rather than self-concept. Response options ranged from 1 (is not true) to 4 (is true) on a 4-point Likert type scale. The items were aggregated by computing a mean value for the factor "general athleticism".

\subsection{Procedure}

Participants were recruited via newspaper advertisements offering a specific walking-program free of charge aimed at enhancing the endurance capability of the elderly. For ethical and medical reasons, willing participants were obligated to prove their physical fitness through a health certificate completed by a physician. After randomly assigning eligible participants to one of the four experimental conditions, an introductory meeting was held prior to the commencement of the 8-week-program in order to prepare the sample for the study. Baseline physical self-concept and physical self-esteem measures were completed at this initial meeting. A few days after the introductory meeting, each experimental condition had its initial walking-session, followed by an eight week 
walking program as described above in the treatment section. After the final walking-session, physical selfconcept and physical self-esteem were measured once again. Thus, physical self-concept and physical self-esteem were measured twice (pre and post) resulting in a $2 \times 2 \times 2$-study-design.

\subsection{Data Analysis}

Data were analyzed using SPSS 22.0. The analysis comprised descriptive and inferential examination of the study variables. In terms of inferential statistics, separate 2 by 2 ANOVAs with repeated measures $(2 \times 2 \times 2$ design) were computed for each of the six dependent variables including: coordination, strength, flexibility, endurance, speediness, general athleticism. The significance level was at $p=0.05$.

\section{Results}

\subsection{Descriptive Statistics}

At the onset of the study, the total mean value for general athleticism across all groups was slightly below the midpoint of the 4-point Likert type scale $(M=2.26, S D=0.58)$. This finding indicates that, overall, the sample had a moderate to low level of self-reported general athleticism. However, the individual values observed ranged from 1 to 4 , indicating a fairly broad range in perceived athleticism. In terms of specific aspects of physical selfconcept, the total mean values of endurance $(M=1.95, S D=0.58)$ and speediness $(M=2.18, S D=0.61)$ were lower than general athleticism. Coordination $(M=2.53, S D=0.57)$, strength $(M=2.32, S D=0.68)$ and flexibility $(M=2.63, S D=0.63)$, however, displayed higher mean values than general athleticism.

After the intervention, general athleticism $(M=2.47, S D=0.60)$ was higher than before; it appeared at the midpoint of the scale with the individual values ranging from 1 to 3.67 . The specific aspects of physical self-concept were higher as well. Again, endurance $(M=2.24, S D=0.64)$ and speediness were below general athleticism, whereas coordination $(M=2.73, S D=0.50)$, strength $(M=2.52, S D=0.67)$ and flexibility $(M=$ $2.79, S D=0.63$ ) were higher than general athleticism. For detailed information concerning the descriptive statistics of each experimental condition, see Table 1.

In terms of the bivariate correlations between the dependent variables, each correlation was significant, except for the correlation between strength and flexibility at the post-measurement (see Table 2). In particular, the correlations between general athleticism and the other variables were invariably large, falling above 0.50 in all instances.

\subsection{Analyses of Variance}

Physical self-concept. Regarding the factor coordination, the ANOVA resulted in a significant within-subject factor: $F(1,62)=19.43, p<0.001, \eta^{2}=0.24$. As shown in Table 1, self-rated coordination increased with time. There were no significant main effects for the instructor: $F(1,62)=0.16, p=0.691, \eta^{2}<0.01$, or group condition: $F(1,62)=0.76, p=0.386, \eta^{2}=0.01$, and no significant two-way-interactions for time $x$ instructor: $F(1,62)$ $=0.07, p=0.800, \eta^{2}<0.01$; time $x$ group: $F(1,62)=2.84, p=0.097, \eta^{2}=0.04$; or instructor $x$ group: $F(1,62)<$ $0.01, p=0.997, \eta^{2}<0.01$.

However, we found a significant three-way-interaction for time $x$ instructor $x$ group: $F(1,62)=8.26, p<$ $0.006, \eta^{2}=0.12$. To further examine this finding, four subsequent ANOVAs were computed. Two ANOVAs were conducted to analyze the two-way-interaction of time $x$ instructor, resulting in a non-significant two-wayinteraction for the individual condition, $F(1,32)=3.44, p=0.073, \eta^{2}=0.10$, and a significant two-way-interaction for the group condition, $F(1,30)=4.90, p=0.035, \eta^{2}=0.14$. As displayed in Figure 1, the latter findings suggests, that the increase of coordination was higher when the group, but not the instructor was present, compared to both the group and the instructor being present (for means see Table 1). Two further ANOVAs showed a non-significant time $x$ group interaction for the no-instructor condition, $F(1,30)=0.54, p=0.467, \eta^{2}$ $=0.02$, and a significant time $x$ group interaction for the instructor condition, $F(1,30)=14.33, p=0.001, \eta^{2}=$ 0.31 , indicating that coordination improved more for study participants walking individually with an instructor compared to those walking in a group with an instructor (see Figure 2).

Regarding strength, the ANOVA resulted in a significant within-subject factor with self-reported strength being higher after the intervention: $F(1,61)=13.05, p=0.001, \eta^{2}=0.18$. No main effects for the instructor: $F(1$, $61)=1.13, p=0.291, \eta^{2}=0.02$; or group conditions: $F(1,61)=1.80, p=0.139, \eta^{2}=0.04$ were found. Moreo- 
Table 1. Mean values of variables measuring physical self-concept and physical self-esteem by condition.

\begin{tabular}{|c|c|c|c|c|c|c|c|c|c|c|c|c|}
\hline \multirow[b]{3}{*}{ Condition (n) } & \multicolumn{4}{|c|}{ Coordination } & \multicolumn{4}{|c|}{ Strength } & \multicolumn{4}{|c|}{ Flexibility } \\
\hline & \multicolumn{2}{|c|}{ Pre } & \multicolumn{2}{|c|}{ Post } & \multicolumn{2}{|c|}{ Pre } & \multicolumn{2}{|c|}{ Post } & \multicolumn{2}{|c|}{ Pre } & \multicolumn{2}{|c|}{ Post } \\
\hline & $M$ & $S D$ & $M$ & $S D$ & $M$ & $S D$ & $M$ & $S D$ & $M$ & $S D$ & $M$ & $S D$ \\
\hline \multicolumn{13}{|l|}{ No-Instructor } \\
\hline No-Group (14) & 2.64 & 0.66 & 2.79 & 0.56 & 2.39 & 0.71 & 2.65 & 0.55 & 2.69 & 0.75 & 2.85 & 0.76 \\
\hline Group (18) & 2.48 & 0.46 & 2.72 & 0.46 & 2.09 & 0.73 & 2.21 & 0.57 & 2.62 & 0.54 & 2.78 & 0.58 \\
\hline Total (32) & 2.55 & 0.55 & 2.75 & 0.50 & 2.23 & 0.72 & 2.41 & 0.59 & 2.65 & 0.63 & 2.81 & 0.66 \\
\hline \multicolumn{13}{|l|}{ Instructor } \\
\hline No-Group (20) & 2.48 & 0.62 & 2.84 & 0.50 & 2.42 & 0.71 & 2.69 & 0.74 & 2.58 & 0.68 & 2.87 & 0.65 \\
\hline Group (14) & 2.56 & 0.56 & 2.54 & 0.50 & 2.38 & 0.56 & 2.52 & 0.72 & 2.67 & 0.58 & 2.62 & 0.53 \\
\hline Total (34) & 2.51 & 0.59 & 2.72 & 0.51 & 2.40 & 0.64 & 2.62 & 0.73 & 2.61 & 0.63 & 2.76 & 0.61 \\
\hline \multicolumn{13}{|l|}{ Total } \\
\hline No-Group (34) & 2.55 & 0.63 & 2.82 & 0.52 & 2.41 & 0.70 & 2.67 & 0.66 & 2.62 & 0.70 & 2.86 & 0.69 \\
\hline Group (32) & 2.52 & 0.50 & 2.64 & 0.48 & 2.22 & 0.66 & 2.35 & 0.65 & 2.64 & 0.55 & 2.71 & 0.56 \\
\hline Total (66) & 2.53 & 0.57 & 2.73 & 0.50 & 2.32 & 0.68 & 2.52 & 0.67 & 2.63 & 0.63 & 2.79 & 0.63 \\
\hline \multicolumn{13}{|l|}{ No-Instructor } \\
\hline No-Group (14) & 1.92 & 0.67 & 2.11 & 0.74 & 1.97 & 0.59 & 2.24 & 0.42 & 2.44 & 0.62 & 2.51 & 0.58 \\
\hline Group (18) & 1.78 & 0.57 & 2.19 & 0.62 & 2.09 & 0.62 & 2.32 & 0.66 & 2.07 & 0.63 & 2.36 & 0.73 \\
\hline Total (32) & 1.84 & 0.61 & 2.15 & 0.67 & 2.04 & 0.60 & 2.29 & 0.56 & 2.23 & 0.64 & 2.43 & 0.66 \\
\hline \multicolumn{13}{|l|}{ Instructor } \\
\hline No-Group (20) & 2.07 & 0.68 & 2.48 & 0.64 & 2.31 & 0.66 & 2.64 & 0.70 & 2.28 & 0.62 & 2.67 & 0.53 \\
\hline Group (14) & 2.02 & 0.28 & 2.13 & 0.49 & 2.32 & 0.50 & 2.33 & 0.66 & 2.31 & 0.37 & 2.27 & 0.50 \\
\hline Total (34) & 2.05 & 0.55 & 2.33 & 0.60 & 2.31 & 0.59 & 2.51 & 0.69 & 2.29 & 0.53 & 2.50 & 0.54 \\
\hline \multicolumn{13}{|l|}{ Total } \\
\hline No-Group (34) & 2.00 & 0.67 & 2.32 & 0.70 & 2.17 & 0.64 & 2.48 & 0.62 & 2.35 & 0.62 & 2.60 & 0.55 \\
\hline Group (32) & 1.89 & 0.48 & 2.16 & 0.56 & 2.19 & 0.57 & 2.33 & 0.65 & 2.17 & 0.54 & 2.32 & 0.63 \\
\hline Total (66) & 1.95 & 0.58 & 2.24 & 0.64 & 2.18 & 0.61 & 2.40 & 0.64 & 2.26 & 0.58 & 2.47 & 0.60 \\
\hline
\end{tabular}

Table 2. Bivariate correlations of variables measuring physical self-concept and physical self-esteem.

\begin{tabular}{ccccccc}
\hline Variable & $(1)$ & $(2) 0$ & $(3)$ & $(4)$ & $(5)$ & $(6)$ \\
\hline (1) Coordination & - & $0.37^{* *}$ & $0.78^{* *}$ & $0.39^{* *}$ & $0.59^{* *}$ & $0.63^{* *}$ \\
(2) Strength & $0.42^{* *}$ & - & $0.31^{* *}$ & $0.42^{* *}$ & $0.52^{* *}$ & $0.59^{* *}$ \\
(3) Flexibility & $0.76^{* *}$ & .22 & - & $0.36^{* *}$ & $0.46^{* *}$ & $0.57^{* *}$ \\
(4) Endurance & $0.46^{* *}$ & $0.47^{* *}$ & $0.34^{* *}$ & - & $0.56^{* *}$ & $0.53^{* *}$ \\
(5) Speediness & $0.67^{* *}$ & $0.53^{* *}$ & $0.54^{* *}$ & $0.57^{* *}$ & - & $0.68^{* *}$ \\
(6) General Athleticism & $0.65^{* *}$ & $0.56^{* *}$ & $0.59^{* *}$ & $0.52^{* *}$ & $0.63^{* *}$ & -
\end{tabular}

${ }^{* *} p<0.01$. The correlations of the pre-measurement are displayed above the diagonal, whereas the correlations of the post-measurement are displayed below. 

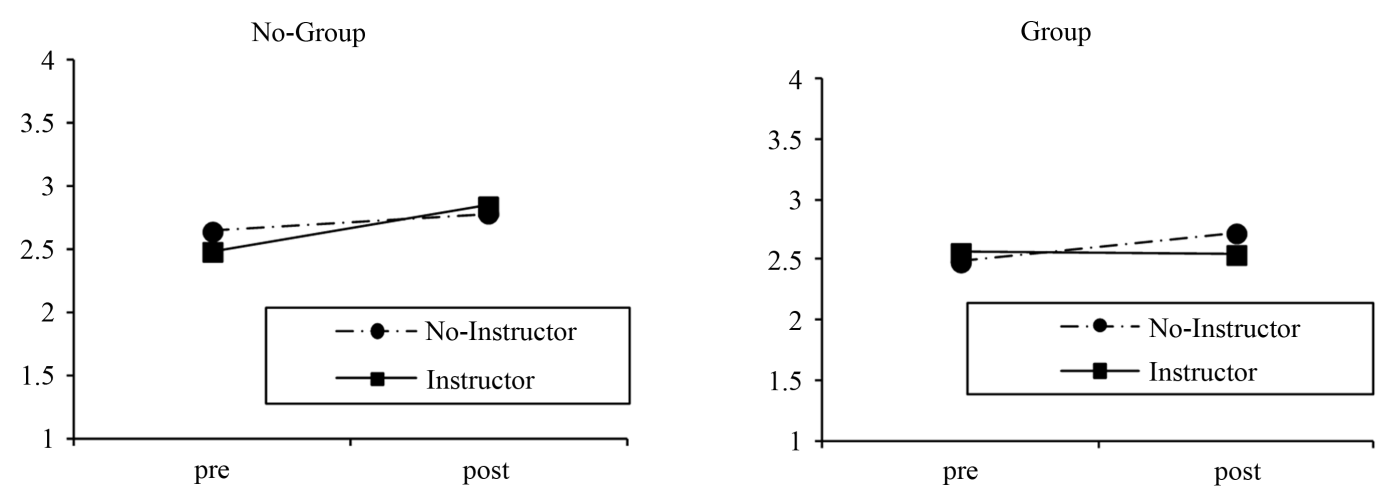

Figure 1. Two-way interaction of time $x$ instructor under the conditions of no-group and group for the dependent variable coordination with possible values ranging from 1 (is not true) to 4 (is true).
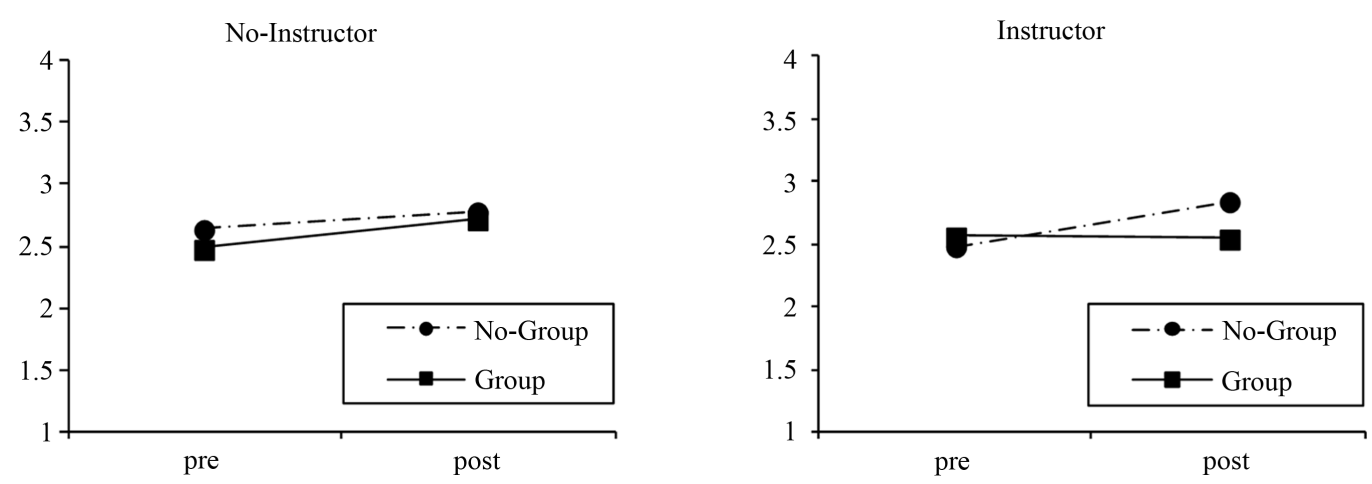

Figure 2. Two-way interaction of time $x$ group under the conditions of no-instructor and instructor for the dependent variable coordination with possible values ranging from 1 (is not true) to 4 (is true).

ver, no interactions effects for time $x$ instructor: $F(1,61)=0.04, p=0.845, \eta^{2}<0.00$; time $x$ group: $F(1,61)=$ 1.53, $p=0.221, \eta^{2}=0.03$; instructor $x$ group: $F(1,61)=0.59, p=0.394, \eta^{2}=0.01$; or time $x$ instructor $x$ group: $F(1,61)<0.01, p=0.973, \eta^{2}<0.01$, were evident.

Similar to the previous results, the ANOVA conducted for flexibility revealed a significant within-subject factor indicating that following the intervention, self-rated flexibility was perceived as higher: $F(1,62)=8.72, p$ $=0.004, \eta^{2}=0.12$. Neither the main effect for instructor: $F(1,62)=0.12, p=0.736, \eta^{2}<0.01$; or group: $F(1,62)$ $=0.23, p=0.631, \eta^{2}<0.01$, emerged as significant, nor were any interaction effects significant for time $x$ instructor: $F(1,62)=0.13, p=0.719, \eta^{2}<0.01$; time $x$ group: $F(1,62)=3.19, p=0.079, \eta^{2}=0.05$; instructor $x$ group: $F(1,62)<0.01, p=0.976, \eta^{2}<0.01$; or time $x$ instructor $x$ group: $F(1,62)=3.30, p=0.074, \eta^{2}=0.05$.

In terms of endurance, the ANOVA resulted in a significant within-subject factor, with self-rated endurance being higher after the intervention: $F(1,62)=30.24, p<0.001, \eta^{2}=0.34$. There were no main effects for the instructor: $F(1,62)=1.54, p=0.219, \eta^{2}=9.02$; or group condition: $F(1,62)=0.61, p=0.436, \eta^{2}=0.01$, nor were any interactions effects evident for time $x$ instructor: $F(1,62)=0.17, p=0.685, \eta^{2}<0.01$; time $x$ group: $F(1,62)$ $=0.17, p=0.679, \eta^{2}<0.01$; or instructor $x$ group: $F(1,62)=0.33, p=0.570, \eta^{2}<0.01$.

Nevertheless, the three-way-interaction (time $x$ instructor $x$ group interaction) was found to be significant: $F(1$, $62)=6.55, p=0.013, \eta^{2}=0.10$. As for the three-way-interaction effect concerning coordination, four subsequent ANOVAs were conducted. Whereas the two-way-interaction of time $x$ instructor emerged as non-significant for the individual condition, $F(1,32)=2.02, p=0.165, \eta^{2}=0.06$, it was significant for the group condition, $F(1,30)=5.26, p=0.029, \eta^{2}=0.15$. Similar to the results concerning coordination, this finding implies that the increase of endurance was higher when the group, but not the instructor was present, compared to both the group and instructor being present. The two-way-interaction of time $x$ group was non-significant for the no-instructor condition, $F(1,30)=2.27, p=0.142, \eta^{2}=0.07$, but significant for the instructor-condition, $F(1,32)=4.48, p=$ $0.042, \eta^{2}=0.12$. Furthermore, consistent with the coordination findings, these results indicate that coordination improved more for study participants walking individually with an instructor compared to those walking in a 
group with an instructor.

Once again, the ANOVA examining speediness indicated a significant within-subject factor: $F(1,62)=13.87$, $p<0.001, \eta^{2}=0.18$. Self-reported speediness was perceived to be higher after the intervention compared to the outset of the study. Congruent with the results for strength and flexibility, neither main effects were found for the instructor: $F(1,62)=2.91, p=0.093, \eta^{2}=0.05$; or group condition: $F(1,62)=0.03, p=0.866, \eta^{2}<0.01$, nor were any interaction effects found for time $x$ instructor: $F(1,62)=0.56, p=0.458, \eta^{2}=0.01$; time $x$ group: $F(1,62)=2.64, p=0.109, \eta^{2}=0.04$; instructor $x$ group: $F(1,62)=0.74, p=0.394, \eta^{2}=0.01$; or time $x$ instructor $x$ group: $F(1,62)=1.66, p=0.202, \eta^{2}=0.03$.

Physical self-esteem. The ANOVA investigating the general athleticism scale also revealed a significant within-subject factor: $F(1,62)=13.93, p<0.001, \eta^{2}=0.18$. No main effects for the two conditions or interaction effects were however, observed: instructor: $F(1,62)=0.08, p=.781, \eta^{2}<0.01$; group: $F(1,62)=2.56, p=$ $0.114, \eta^{2}=0.04$; time $x$ instructor interaction: $F(1,62)<0.01, p=.938, \eta^{2}<0.01$; time $x$ group interaction: $F(1$, $62)=1.05, p=0.309, \eta^{2}=0.02$; instructor $x$ group interaction: $F(1,62)=0.08, p=0.784, \eta^{2}<0.01$.

The three-way-interaction (time $x$ instructor $x$ group interaction) was significant, $F(1,62)=11.43, p=0.001$, $\eta^{2}=0.16$, resulting in four subsequent ANOVAs, computed according to the procedure described above. The two-way-interaction of time $x$ instructor emerged as significant for the individual condition, $F(1,32)=5.90, p=$ $0.021, \eta^{2}=0.16$, as well as for the group condition, $F(1,30)=5.53, p=0.025, \eta^{2}=0.16$. As displayed in Figure 3 , these findings suggest that general athleticism improved more for study participants walking individually with an instructor than for those walking individually without an instructor. These findings also indicate that the increase in general athleticism was higher when the group, but not the instructor was present, compared to both the instructor and the group being present.

The two-way-interaction of time $x$ group was non-significant for the non-instructor condition, $F(1,30)=3.22$, $p=0.083, \eta^{2}=0.10$, but significant for the instructor-condition, $F(1,32)=8.65, p=0.006, \eta^{2}=0.21$. These results are illustrated in Figure 4, revealing that general athleticism improved more for study participants walking individually with an instructor compared to those walking in a group with an instructor.
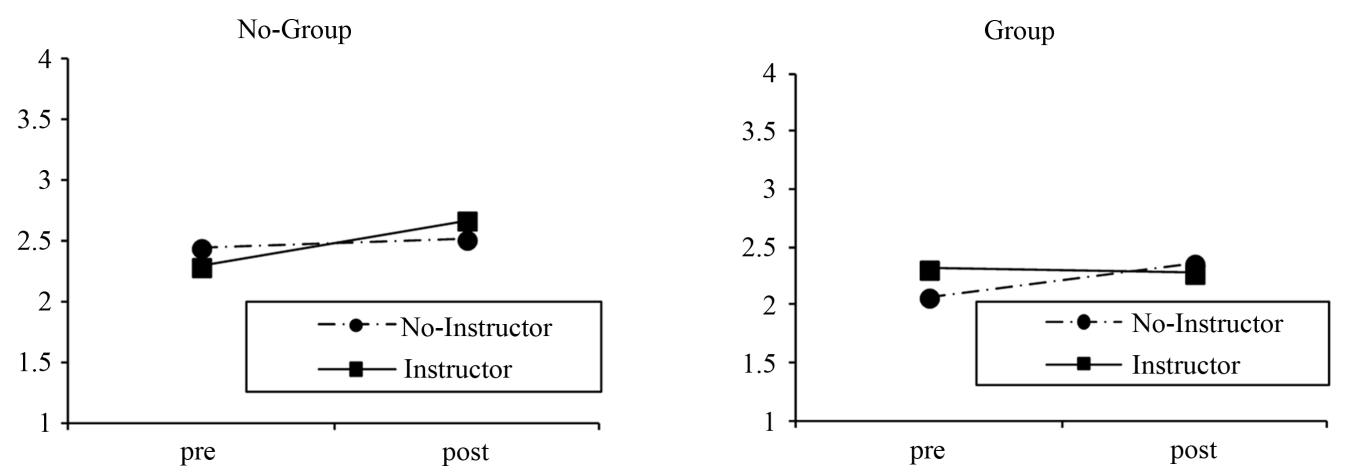

Figure 3. Two-way interaction of time $x$ instructor under the conditions of no-group and group for the dependent variable general athleticism with possible values ranging from 1 (is not true) to 4 (is true).
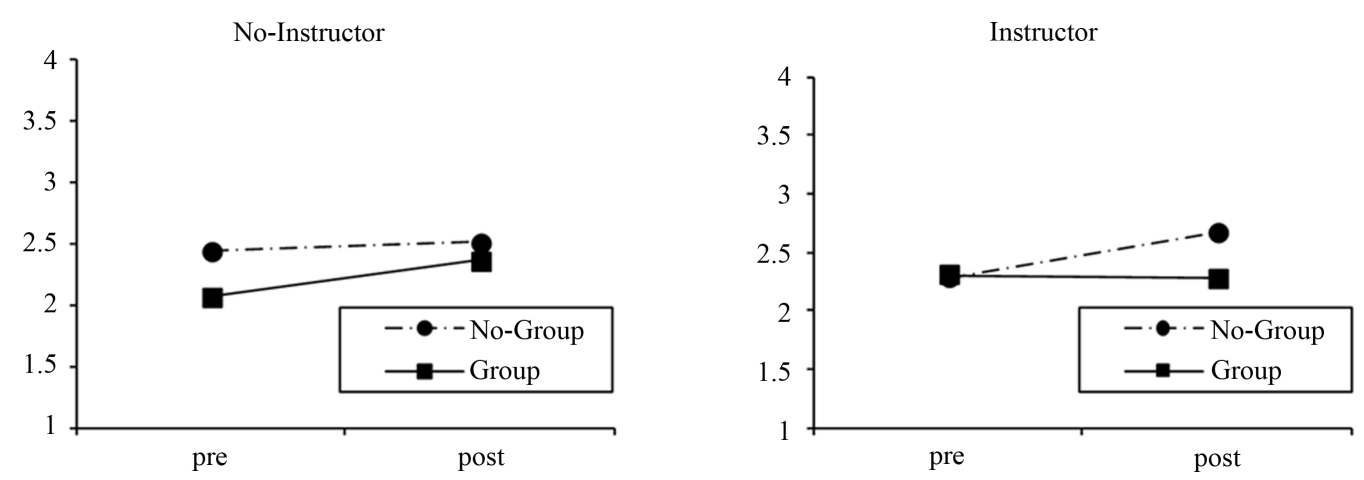

Figure 4. Two-way interaction of time $x$ group under the conditions of no-instructor and instructor for the dependent variable general athleticism with possible values ranging from 1 (is not true) to 4 (is true). 


\section{Discussion}

Previous research indicates that exercise leads to an enhancement in physical self-concept and physical self-esteem [3] [11]. Furthermore, both health and sport science research [14] [16] reveal that the presence of others helps to explain the link between exercise, self-concept, and self-esteem. What has remained unexamined, is whether different types of individuals within the exercise setting (i.e., an instructor and/or other group members) have different impacts on the development of physical self-concept and esteem.

Against this backdrop, results from our investigation provide initial evidence that different social environments lead to different effects on physical self-concept and physical self-esteem. Specifically, we demonstrated that both the presence of an instructor and the presence of other group members during a walking program resulted in a significant and marked increase in physical self-concept and self-esteem. Under both conditions, the improvement of the physical self was significantly higher compared with the experimental condition in which no increase in physical self-concept and physical self-esteem was observed. Interestingly, this "no-effect-condition" occurred, when both the instructor and group members had been present simultaneously. In the no-instructor/ no-group condition (i.e., when the participant exercised completely independently), a moderate increase occurred, which was not significantly different to the no-instructor/group, instructor/no-group, and instructor/ group conditions (for an overview of the results see Figure 5). These results were evident for the self-esteem and the self-concept areas of endurance and coordination but not for strength, flexibility, and speediness. One possible explanation for this particular effect is that the walking program specifically addressed endurance and coordination.

Overall, results regarding the impact of different individuals in the exercise environment on elder adults' self-concept and esteem can be interpreted by taking into account the constructs of social support and social integration articulated in the introduction. First, with regard to the effect of the presence of the instructor on elder adults' physical self-concept and esteem, social support mechanisms [14] may be particularly relevant. As Cohen suggests, the presence of other people may serve a social support function by helping individuals cope with external demands. In turn, an individual's experience of positive coping leads to an increase in perceived efficacy and control [4], which results in higher self-concept and self-esteem. In this regard, the exercise instructor is a person, who shows the participant, that he or she is able to handle the exercise tasks. Moreover, the instructor is-especially in a one-to-one-condition—able to define important training parameters (e.g., training intensity) which are consistent with the competence level of the individual and thus are likely to lead to the individual's success. Exercise success in turn, is a main source of positive physical self-concept and physical self-esteem [9]. It may also be that the specific type of support offered by the instructor versus the group (e.g., instrumental support, emotional support, listening support) has implications for the development of elder adults' self-concept and esteem. While instructors may be more inclined to provide instrumental forms of support (e.g., assistance in helping exercisers maximize their walking proficiency), group members may be more involved in the provision of emotional support. Hence, it seems plausible that different types of support may be offered by different individuals (e.g., instructor versus a group) and that certain forms of support are more (or less) relevant in the development of physical self-concept and esteem among elder adult exercisers. Further research examining such contentions is warranted.

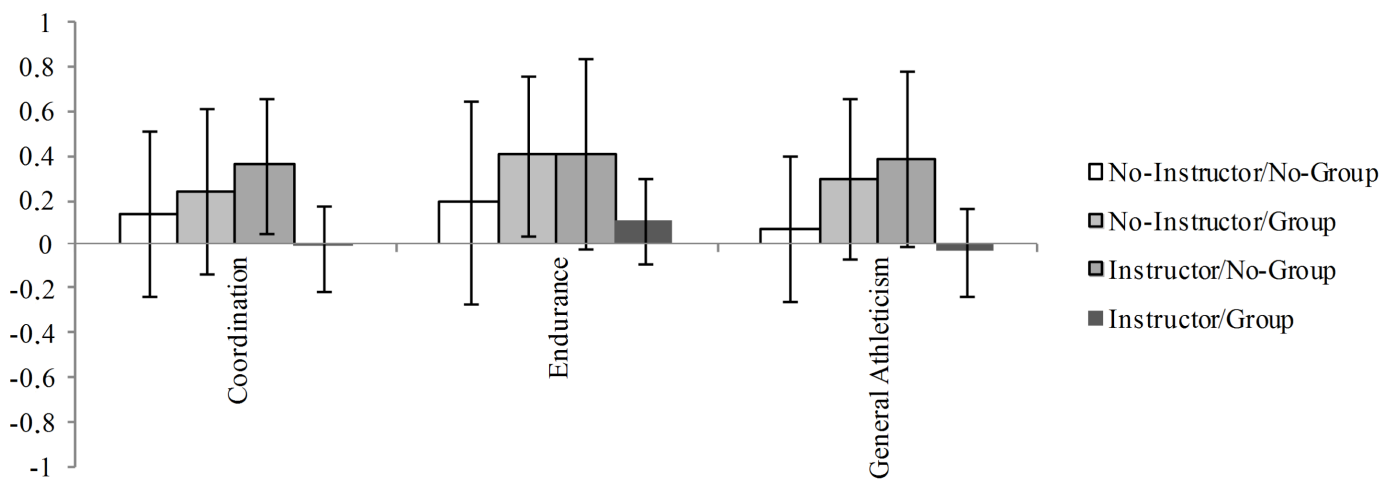

Figure 5. Mean difference of each experimental condition in coordination, endurance and general athleticism comparing pre to post measurements with positive values indicating higher post-values. 
Second, in terms of the positive impact of the presence of the group on participants' physical self-concept and physical self-esteem, the social integration approach [14] may hold greater relevance than social support explanations. According to Cohen's social integration approach, being part of a group-in this case an exercise group - is connected to the development of a social identity. A person's social identity — as an essential origin of the self-description and the self-evaluation of a person-is connected with an increase in self-esteem [2]. Given this process, groups are functional since they satisfy an individual's need for positive self-esteem by allowing one to affiliate and identify with socially valued activities and ideals [15].

The process of identity-development in exercise groups has been previously discussed in the literature [16] [17]. Linking this discussion with the results of our study would lead to an interesting and necessary research approach, in which identity is assumed to mediate the relationship between exercise and self-esteem enhancement. However, further research is needed to examine whether such a mechanism is limited to the relationship between an individual and his or her group, or whether the relationship between the individual and the instructor also contains the potential for positive identity development (i.e., partnership identity). Moreover, there may be numerous variables that moderate the relationship between exercise, social identity, and self-esteem. One such variable is the group climate. In particular, the extent to which an ego versus task climate (i.e., normative/other based comparisons versus self-referenced improvement and task mastery) predominates within an exercise group may foster positive or negative forms of social comparison within the group (e.g., feeling good about collective improvements in endurance versus feeling self-defeated by comparisons with other group members who consistently walk faster). In instances where an ego-oriented climate is pervasive, it could be expected that the positive effects of exercise on self-esteem may be mitigated for most group members [22]. In this case, the "bigfish-little-pond" effect may be in evidence whereby social identity increases for a select number of participants (i.e., the best ones), while the majority experience self-esteem decrements [23].

A third finding of importance was that when both the instructor and group were present, neither physical selfconcept nor physical self-esteem increased. Upon initial reflection, this result is very surprising, since it could be assumed, that the presence of the instructor in addition to a group would hold greater potential for social support and integration than the presence of one, but not the other (a leader but no group or vice-versa). Moreover, if both a group leader and group members are present, an individual might be able to choose whether the instructor or group members are more helpful for their personal coping and development. Such reasoning begs the question: Why then, was there no positive effect on physical self-concept or self-esteem under this condition? One possibility is that the concurrent existence of a leader and a group may lead to a sort of psychic confusion, whereby the individual is forced to develop two social identities (i.e., individual-instructor-identity and an individual-group-identity) at the same time. In instances where the underlying identity characteristics are different (e.g., different goals or attitudes in terms of exercise between instructor and group members), such differences could lead to cognitive dissonance regarding both identities. In such instances, confusion would likely increase, while self-esteem would presumably decrease. An alternative explanation is that even though the instructor may potentially facilitate improvements in self-concept and esteem (e.g., in providing information indicating positive exercise gains or improvements), processes of social comparison inhibit these improvements. These processes base on the fact that since the instructor helped all group members similarly to improve their performance, the performance position of every single group member in relation to the whole group remained at a similar level (compared pre to post). As such, if group members compare themselves with others in the group no relative improvements in this position and thus no improvements in physical self-concept or physical esteem were observed.

Finally, a reason for the absence of effects under the instructor/group condition could be, that in this situation the instructor would obviously have less time to consult and demonstrate care for specific individuals than under the instructor/no group (i.e., one-on-one instruction) condition. For an instructor to be effective in a group setting, he or she is required to provide attention and care to numerous participants. Conversely, in one-on-one situations, the exerciser receives the instructor's complete attention and care and is able to receive more individual feedback and information on beneficial training loads and demands. Thus, in the instructor/no group condition, the feeling of being recognized and esteemed is likely greater, and therefore self-esteem is enhanced.

As in any investigation, several limitations exist. In the present study, participant issues, treatment issues, and measurement issues were apparent. In terms of participant issues, all exercisers had been recruited via newspaper advertisements. Thus, it can be expected that such persons were positively motivated and possessed at least moderate levels of self-esteem. Our results therefore may not be easily transferred to older people in general. 
Furthermore, the 17 participants who dropped out of the study were unequally distributed across the four experimental conditions.

Measurement issues were also apparent in the present study. Since we were only interested in the development of physical self-concept and physical self-esteem, we did not consider physical attractiveness. However, the amount of self-rated attractiveness is another important variable which may influence the degree of global physical self-esteem [24]. Thus, future research should take into account the relationship between competencedriven self-esteem (i.e., the approach of the current study) and attractiveness-driven self-esteem.

A final limitation regarding treatment issues was also evident. In particular, differences in instructor personalities may have influenced self-esteem development among participants in the instructor conditions. It seems plausible that many personal attributes of the instructor (e.g., empathy, trustworthiness, communication) are responsible for the extent of the instructor's influence on physical self-concept and physical self-esteem. In our experiment, due to organizational reasons, more than one instructor was included; thus the instructors were not exactly the same individuals under all experimental conditions. Researchers should therefore control for potential confounding effects regarding the instructor's personality by using the same instructor for each condition.

Despite these limitations, findings from the present study are novel in demonstrating that even if the presence of others seems to be helpful for the positive development of physical self-concept and physical self-esteem, such development does not occur equally under all social circumstances. Specifically, the constellation of the social environment, that is, the amount and kind of people who are present, and the interaction of different persons in different roles (e.g., formal or informal leaders) seem to be of particular importance in influencing physical self-concept and physical self-esteem. Thus, the influence of group structure and interpersonal behaviors within exercise groups on the personal development and growth of individual exercisers requires further empirical examination.

\section{Acknowledgements}

The present study was funded by the German health insurance company "GEK—Gmünder Ersatzkasse". Many thanks to Dr. Babett Lobinger for her support in organizing the study and collecting the data.

\section{References}

[1] Diener, E. (1984) Subjective Well-Being. Psychological Bulletin, 95, 542-575. http://dx.doi.org/10.1037/0033-2909.95.3.542

[2] Swann, W.B. and Bosson, J.K. (2010) Self and Identity. In: Fiske, S.T., Gilbert, D.T. and Lindzey, G., Eds., Handbook of Social Psychology, 5th Edition, Wiley, Hoboken, 589-628.

[3] Fox, K.R. (2000) The Effects of Exercise on Self-Perceptions and Self-Esteem. In: Biddle, S.J., Fox, K.R. and Boutcher, S.H., Eds., Physical Activity and Psychological Well-Being, Routledge, London, 88-117.

[4] Thoits, P.A. (2011) Mechanisms Linking Social Ties and Support to Physical and Mental Health. Journal of Health and Social Behavior, 52, 145-161. http://dx.doi.org/10.1177/0022146510395592

[5] Ferreira, J.P., Teixeira, A.M., Massart, A.G. and Filaire, E. (2013) Assessing Self-Esteem and Perceived Physical Competence in Elderly Using the Physical Self-Perception Profile. European Journal of Adapted Physical Activity, 6, 7-18.

[6] Robins, R.W., Trzesniewski, K.H., Tracy, J.L., Gosling, S.D. and Potter, J. (2002) Global Self-Esteem across the Life Span. Psychology and Aging, 17, 423-434. http://dx.doi.org/10.1037/0882-7974.17.3.423

[7] Torres, R. and Fernández, F. (1995) Self-Esteem and Value of Health as Determinants of Adolescent Health Behavior. Journal of Adolescent Health, 16, 60-63. http://dx.doi.org/10.1016/1054-139X(94)00045-G

[8] Fox, K.R. and Corbin, C. (1989) The Physical Self-Perception Profile: Development and Preliminary Validation. Journal of Sports \& Exercise Psychology, 11, 408-430.

[9] Sonstroem, R. and Morgan, W. (1989) Exercise and Self-Esteem: Rationale and Model. Medicine \& Science in Sports \& Exercise, 21, 329-337. http://dx.doi.org/10.1249/00005768-198906000-00018

[10] Marsh, H.W., Asci, F.H. and Tomás, I.M. (2002) Multitrait Multimethod Analyses of Two Physical Self-Concept Instruments: A Cross-Cultural Perspective. Journal of Sport \& Exercise Psychology, 24, 99-119.

[11] Netz, Y., Wu, M.-J., Becker, B.J. and Tenenbaum, G. (2005) Physical Activity and Psychological Well-Being in Advanced Age: A Meta-Analysis of Intervention Studies. Psychology and Aging, 20, 272-284.

http://dx.doi.org/10.1037/0882-7974.20.2.272 
[12] McAuley, E., Blissmer, B., Katula, J., Duncan, T.E. and Mihalko, S.L. (2000) Physical Activity, Self-Esteem, and SelfEfficacy Relationships in Older Adults: A Randomized Controlled Trial. Annals of Behavioral Medicine, 22, 131-139. http://dx.doi.org/10.1007/BF02895777

[13] Alfermann, D. and Stoll, O. (2000) Effects of Physical Exercise on Self-Concept and Well-Being. International Journal of Sport Psychology, 30, 47-65.

[14] Cohen, S. (2004) Social Relationships and Health. American Psychologist, 59, 676-684. http://dx.doi.org/10.1037/0003-066X.59.8.676

[15] Hogg, M.A. and Turner, J.C. (1985) Interpersonal Attraction, Social Identification and Psychological Group Formation. European Journal of Social Psychology, 15, 51-66. http://dx.doi.org/10.1002/ejsp.2420150105

[16] Prapavessis, H. and Carron, A.V. (1996) The Effect of Group Cohesion on Competitive State Anxiety. Journal of Sport \& Exercise Psychology, 18, 64-74.

[17] Spink, K.S. and Carron, A.V. (1992) Group Cohesion and Adherence in Exercise Classes. Journal of Sport \& Exercise Psychology, 14, 78-86.

[18] McAuley, E., Blissmer, B., Marquez, D.X., Jerome, G.J., Kramer, A.F. and Katula, J. (2000) Social Relations, Physical Activity and Well-Being in Older Adults. Preventive Medicine, 31, 608-617. http://dx.doi.org/10.1006/pmed.2000.0740

[19] Borg, G. (1982) Psychophysical Bases of Perceived Exertion. Medicine and Science in Sports and Exercise, 14, 377381. http://dx.doi.org/10.1249/00005768-198205000-00012

[20] Marsh, H.W. and Redmayne, R. (1994) A Multidimensional Physical Self-Concept and Its Relations to Multiple Components of Physical Fitness. Journal of Sport \& Exercise Psychology, 16, 43-55.

[21] Stiller, J., Würth, S. and Alfermann, D. (2004) Die Messung des physischen Selbstkonzepts (PSK): Zur Entwicklung der PSK-Skalen für Kinder, Jugendliche und Junge Erwachsene. Zeitschrift für Differentielle und Diagnostische Psychologie, 25, 239-257. http://dx.doi.org/10.1024/0170-1789.25.4.239

[22] Reinboth, M. and Duda, J.L. (2004) The Motivational Climate, Perceived Ability, and Athletes’ Psychological and Physical Well-Being. The Sport Psychologist, 18, 237-251.

[23] Chanal, J.P., Marsh, H.W., Sarrazin, P.G. and Bois, J.E. (2005) Big-Figh-Little-Pond Effects on Gymnastics Self-Concept: Social Comparison Processes in a Physical Setting. Journal of Sport \& Exercise Psychology, 27, 53-70.

[24] Fox, K.R. (1997) The Physical Self and Processes in Self-Esteem Development. In: Fox, K.R., Ed., The Physical Self. From Motivation to Well-Being, Human Kinetics, Champaign, 111-140. 
Scientific Research Publishing (SCIRP) is one of the largest Open Access journal publishers. It is currently publishing more than 200 open access, online, peer-reviewed journals covering a wide range of academic disciplines. SCIRP serves the worldwide academic communities and contributes to the progress and application of science with its publication.

Other selected journals from SCIRP are listed as below. Submit your manuscript to us via either submit@scirp.org or Online Submission Portal.
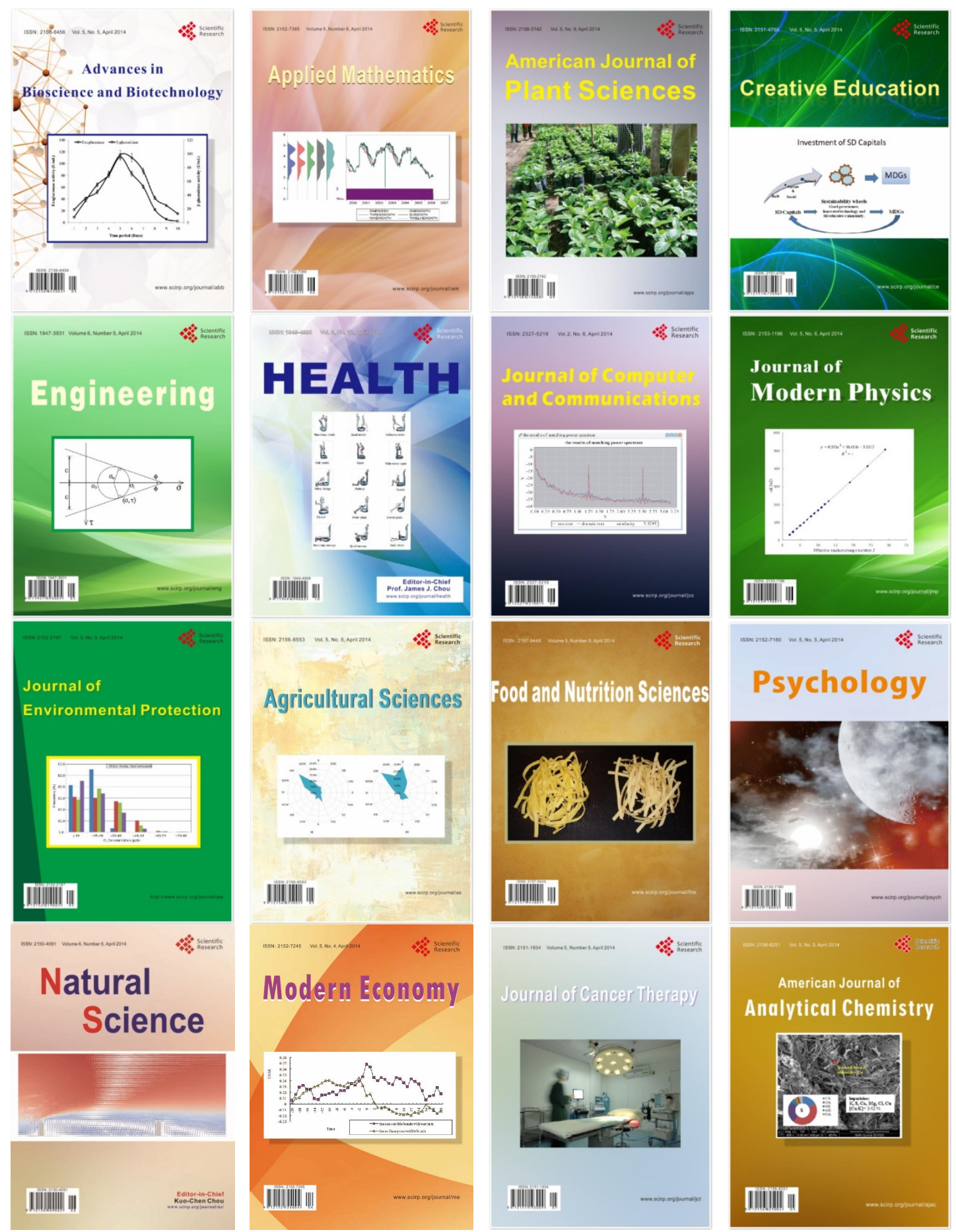